\title{
CESIUM-137 IN LAKE MICHIGAN SEDIMENTS: AREAL DISTRIBUTION AND CORRELATION WITH OTHER MAN-MADE MATERIALS
}

\author{
Phillip A. Plato \& A. P. Jacobson \\ Department of Environmental and Industrial Health, \\ The University of Michigan, Ann Arbor, Michigan 48104, USA
}

\begin{abstract}
Grab samples of sediment were collected at 530 locations in Lake Michigan, primarily in the southeastern quarter of the lake. Each sample was analysed in the field and in the laboratory for fallout cesium-137. Twenty-five of the samples, collected near the mouth of the St Joseph River, were also analysed in the laboratory for 11 other man-made materials known to be discharged into the river. Two statistical methods were used to determine if cesium-137 can be used as an environmental tracer to predict the areal distributions of other man-made materials. The results show fallout cesium-137 to be a moderate to good tracer for locating areas of accumulation of plutonium-238, plutonium-239, zinc, copper, chromium, lead, dieldrin, DDT and PCB in sediment. Little or no correlation is found between fallout cesium-137 and strontium-90 or nickel.
\end{abstract}

\section{INTRODUCTION}

A study was conducted in 1970 to measure radioactivity in Lake Michigan before a total of ten nuclear power plants, designed to produce about $7100 \mathrm{MWe}$, became operational around the lake (Golden et al., 1970). Only one nuclear power plant, producing $70 \mathrm{MWe}$, was operational at the time of the study. As part of the 1970 study, samples of sediment were collected at 50 stations located throughout the lake. Each sample was analysed in the laboratory for gamma-ray emitting radionuclides. Fallout cesium-137 was the only man-made radionuclide detected in any of the sediment samples. Contour lines were drawn among the 50 sampling stations to describe the areal distribution of cesium-137 in the sediments of Lake Michigan (Plato, 1972). The contour lines showed that the majority of the cesium-137 that had been deposited in the sediment was located in the southern half of the lake, primarily in the southern quarter. 
In 1972, additional sediment samples were collected at 185 stations near the mouth of the St Joseph River in southeastern Lake Michigan. Analyses of these samples showed high concentrations, about eight times higher than were found in the 1970 study, of fallout cesium-137 in lake sediments in an area extending approximately 8 to $35 \mathrm{~km}$ from the shore and $25 \mathrm{~km}$ parallel to the shore on either side of the mouth of the St Joseph River (Plato \& Goldman, 1972). This area had been sampled by only two of the 50 stations examined as part of the 1970 study. These two stations, when combined with the other 48 stations from the 1970 study, did not reflect the pronounced influence that a major river has on the concentrations of cesium-137 in the sediments near the mouth of the river. Thus, the results of the 1972 study showed, among other things, that the 50 stations sampled for the 1970 study were inadequate to describe accurately the areal distribution of cesium-137 in the sediments of a lake as large as Lake Michigan.

In 1973, additional sediment samples were collected in the southeastern quarter of Lake Michigan. Analyses of sediment samples collected from the 530 sediment sampling stations in Lake Michigan from 1970 to 1973 have been combined in this paper to determine:

(1) A more accurate estimate of the areal distribution of cesium-137 in the sediments of Lake Michigan than was possible from the results of the 1970 study.

(2) If cesium-137 can be used as an environmental tracer to predict the areal distributions of other man-made materials in the sediments of a large lake.

\section{PROCEDURE}

Figure 1 shows the locations of 530 sediment sampling stations in .Lake Michigan. All samples were collected with a small dredge. The dredge collects a block of sediment over a surface of approximately $23 \mathrm{~cm}$ by $23 \mathrm{~cm}$ to a depth of about $8 \mathrm{~cm}$. The 1970 samples were collected by the crew of the University of Michigan's research vessel Mysis. The exact procedure followed by the crew when removing the samples from the dredge was not recorded. For the samples collected after 1970, the top $3 \mathrm{~cm}$ were removed as carefully as possible from each block of sediment collected by the dredge. Two blocks were collected at each station and combined to form a single sample of approximately 3 litres of wet sediment.

Each sample collected after 1970 was counted for $200 \mathrm{sec}$ aboard ship for cesium137 with a $7.5 \mathrm{~cm}$ diameter by $7.5 \mathrm{~cm}$ thick sodium iodide detector coupled to a 200-channel pulse height analyser. The count rate under the cesium-137 photopeak was used as a measure of the relative concentration of cesium-137 in each sample. The minimum detectable count rate of cesium-137 with this procedure is 10 counts $/ \mathrm{min} / \mathrm{sample}$. The relative cesium-137 content of the sediment samples analysed in the field ranged from $<10$ to 470 counts $/ \mathrm{min}$. This rapid and inexpen- 


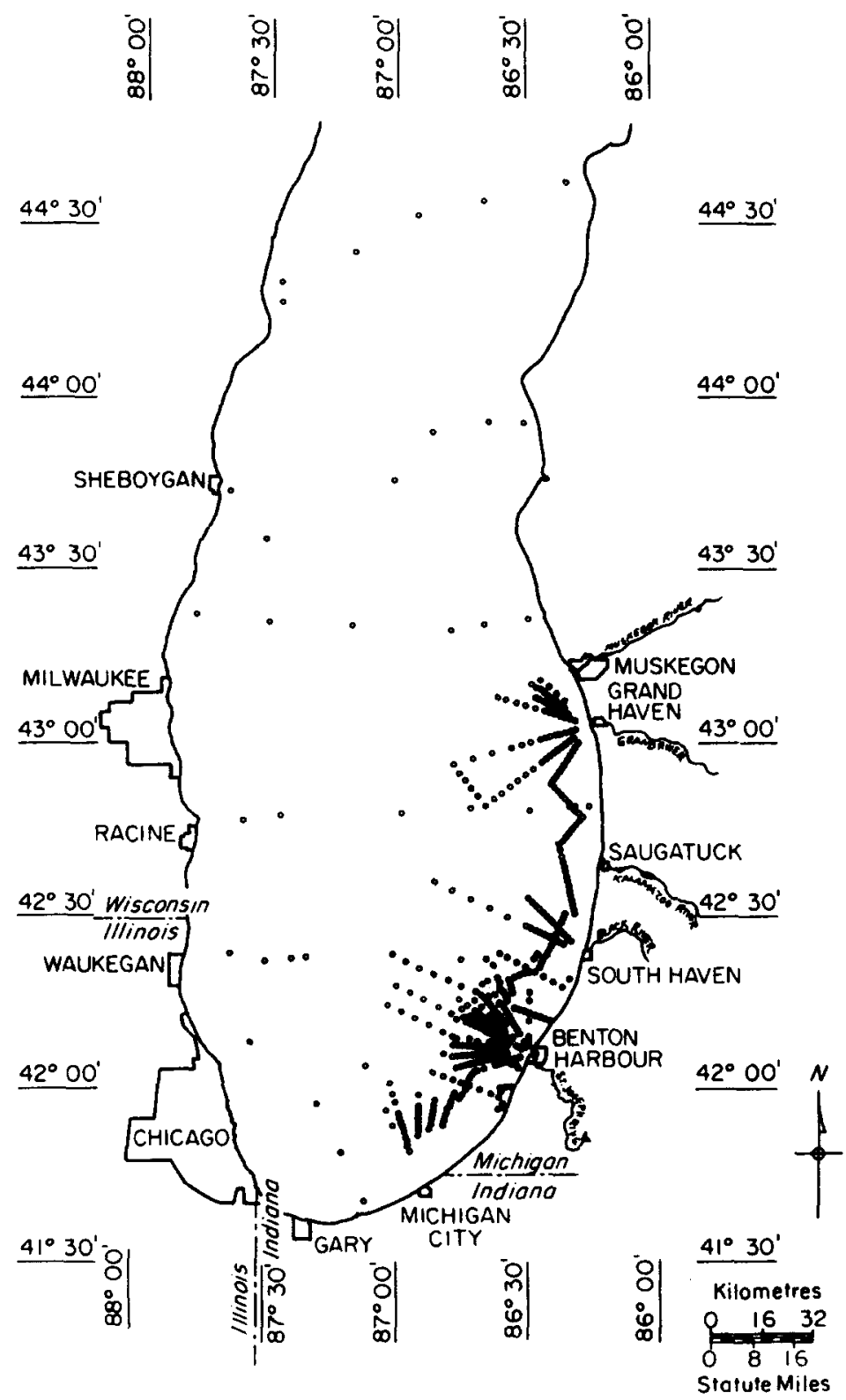

Fig. 1. Relative locations of the 530 sediment stations in Lake Michigan sampled from 1970 to 1973 . 
sive field method enabled decisions to be made aboard ship each night concerning areas of sediment to be studied in detail the following day.

Each sediment sample was transported to the laboratory and dried. Weighed amounts of each sample were counted for cesium-137 with a $12.7 \mathrm{~cm}$ diameter by $10.2 \mathrm{~cm}$ thick sodium iodide detector coupled to a 256 -channel pulse height analyser. Each gamma-ray spectrum was analysed by our computer-programmed least-squares technique of spectrum stripping. Concentrations of cesium-137 were calculated in units of picocuries/dry gramme of sediment $(\mathrm{pCi} / \mathrm{g}$ ). The minimum detectable concentration of cesium- 137 with the laboratory procedure is $0.03 \mathrm{pCi} / \mathrm{g}$. The range of cesium- 137 concentrations among the 530 sediment samples was 0.06 to $13.88 \mathrm{pCi} / \mathrm{g}$.

Use of a dredge to collect the sediment samples presents two potential problems. First, the samples represent the top $3 \mathrm{~cm}$ of sediment, excluding the 50 samples from the 1970 study which probably represent the top $8 \mathrm{~cm}$. Analyses of sediment cores taken in Lake Michigan show a vertical distribution of cesium-137 ranging from less than $1 \mathrm{~cm}$ in the southwestern quarter of the lake to about $6 \mathrm{~cm}$ in the southeastern quarter of the lake (Robbins \& Edgington, 1975). Thus, it is possible that a portion of each sample collected where the sedimentation rate is low contains sediment with little or no cesium-137. The resulting concentration value would be lower than that which actually exists at the surface of the sediment. The second problem with the use of a dredge is that some of the very fine sediment at the top of a sample may wash out of the dredge during collection. Both of these potential problems contribute to the overall uncertainty associated with each measurement.

AREAL DISTRIBUTION OF CESIUM-137

Contour lines showing concentrations of cesium-137 in the sediments of southern Lake Michigan can be seen in Fig. 2 and contour lines showing relative water depths of the lake in Fig. 3. A comparison of Figs. 2 and 3 shows that, at water depths less than about $100 \mathrm{ft}(30 \mathrm{~m})$ around the periphery of the lake, cesium-137 concentrations in bottom sediments are less than $1 \mathrm{pCi} / \mathrm{g}$. Effects of wave action and turbulence on the bottom, especially during storms, apparently prevent large concentrations of cesium-137 from accumulating in sediments at water depths much less than $30 \mathrm{~m}$.

We believe the most likely route by which fallout cesium-137 accumulates in the sediments of the lake is by adsorption onto suspended particles which eventually settle to the bottom. Suspended solids within a river have sufficient time to adsorb ions of cesium-137 that have washed out of the surrounding watershed or that have fallen directly into the river. Suspended solids discharged by a river into Lake Michigan will follow the water current patterns of the lake as they settle to the bottom. 


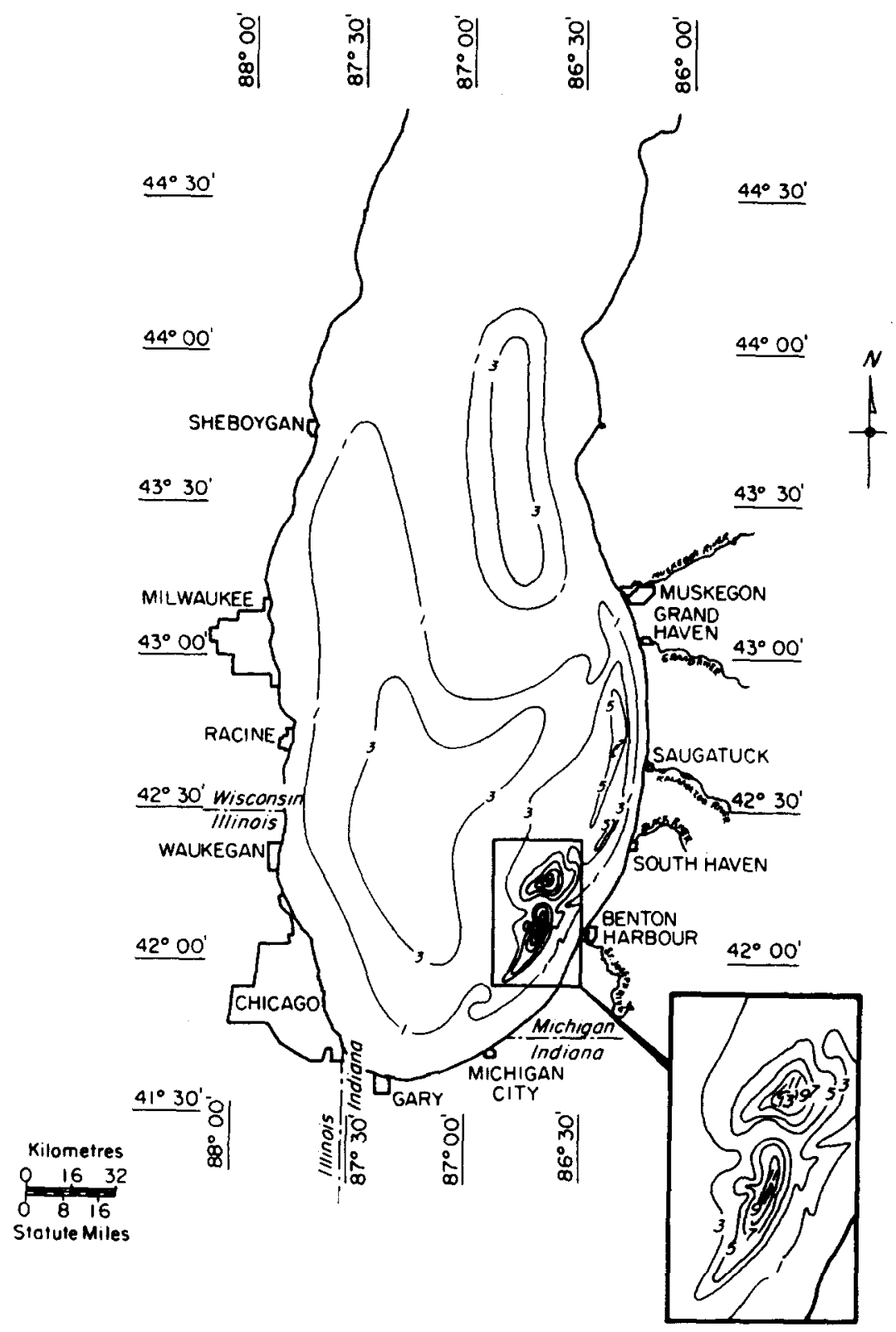

Fig. 2. Concentration of cesium-137 in the sediments of Lake Michigan in units of $\mathrm{pCi} / \mathrm{g}$, dry weight. 


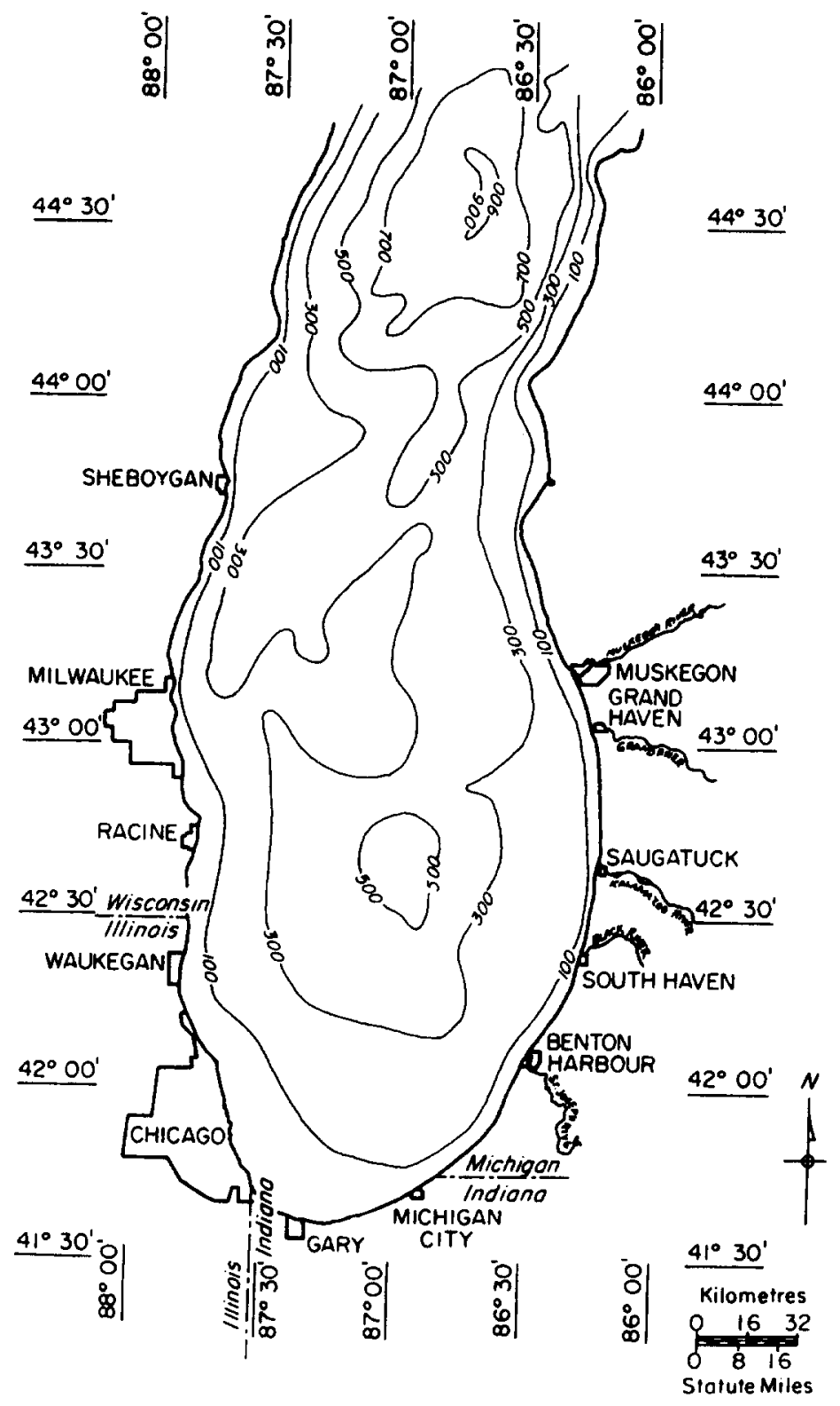

Fig. 3. Water depths of Lake Michigan in units of $\mathrm{ft}$. 
TABLE 1

AVERAGE FLOW RATES AND SUSPENDED SOLID CONTENTS AND DISCHARGE RATES OF THE MAJOR RIVERS IN MICHIGAN THAT DISCHARGE THEIR WATERS INTO LAKE MICHIGAN (STATE OF MICHIGAN, 1968)

\begin{tabular}{lccc}
\hline \multirow{2}{*}{ River } & \multirow{2}{*}{$\begin{array}{c}\text { Flow rate } \\
\text { (103 litres/sec) }\end{array}$} & \multicolumn{2}{c}{ Suspended solids } \\
\cline { 3 - 4 } & & (mg/litre) & $\left(10^{7} \mathrm{~kg} / \mathrm{y}\right)$ \\
\hline St Joseph & 136 & 25 & $10 \cdot 7$ \\
Black & 32 & 13 & $1 \cdot 3$ \\
Kalamazoo & 49 & 16 & $2 \cdot 5$ \\
Grand & 132 & 15 & $6 \cdot 3$ \\
Muskegon & 67 & 8 & $1 \cdot 7$ \\
White & 14 & 9 & $0 \cdot 4$ \\
Pentwater & $\mathrm{a}$ & 6 & $\mathrm{a}$ \\
Pere Marquette & 19 & 10 & $0 \cdot 6$ \\
Manistee & 60 & 8 & 1.5 \\
Boardman & 7 & 5 & $0 \cdot 1$ \\
Pine & $\mathrm{a}$ & 4 & $\mathrm{a}$ \\
Cheboygan & 35 & 6 & 0.7 \\
\hline
\end{tabular}

- Flow rate data not available.

Suspended solids in the lake may also adsorb cesium- 137 and other materials that fall directly into the lake. For example, lead from automobile exhausts has been shown to accumulate in bottom sediments as a result of direct fallout into a large body of water (Chow et al., 1973).

Figure 4 shows typical surface water current patterns for Lake Michigan measured during the summer of 1955 (Ayers et al., 1958). Table 1 shows average flow rates and suspended solid contents and discharge rates of major rivers in Michigan that discharge their waters into Lake Michigan (State of Michigan, 1968). A few additional rivers discharge into the lake from Indiana, Illinois and Wisconsin, but their contributions are minor compared with the contributions from Michigan rivers. Some similarities can be seen between the concentrations of cesium-137 in bottom sediments (Fig. 2) and the combined effects of suspended solids discharge rates from surrounding rivers (Table 1) and surface water current patterns (Fig. 4). A large area of sediment that contains relatively high concentrations of cesium-137 exists near the mouth of the St Joseph River, which has the highest discharge rate of suspended solids. Small areas of sediment that contain relatively high concentrations of cesium-137 exist near the mouths of the Black and Kalamazoo Rivers, which have suspended solids discharge rates of about $10 \%$ and $25 \%$, respectively, of the St Joseph River. However, no accumulation of cesium-137 appears to exist in the sediments near the mouth of the Grand River, which has a suspended solids discharge rate of about $60 \%$ of the St Joseph River. Surface water currents, and possibly subsurface water currents, near the Grand River, apparently distribute suspended solids over a wide area to the south of the river.

An extensive study was conducted by Powers \& Robertson (1968) to determine the areal distribution of sediment types in Lake Michigan. They defined five types of 


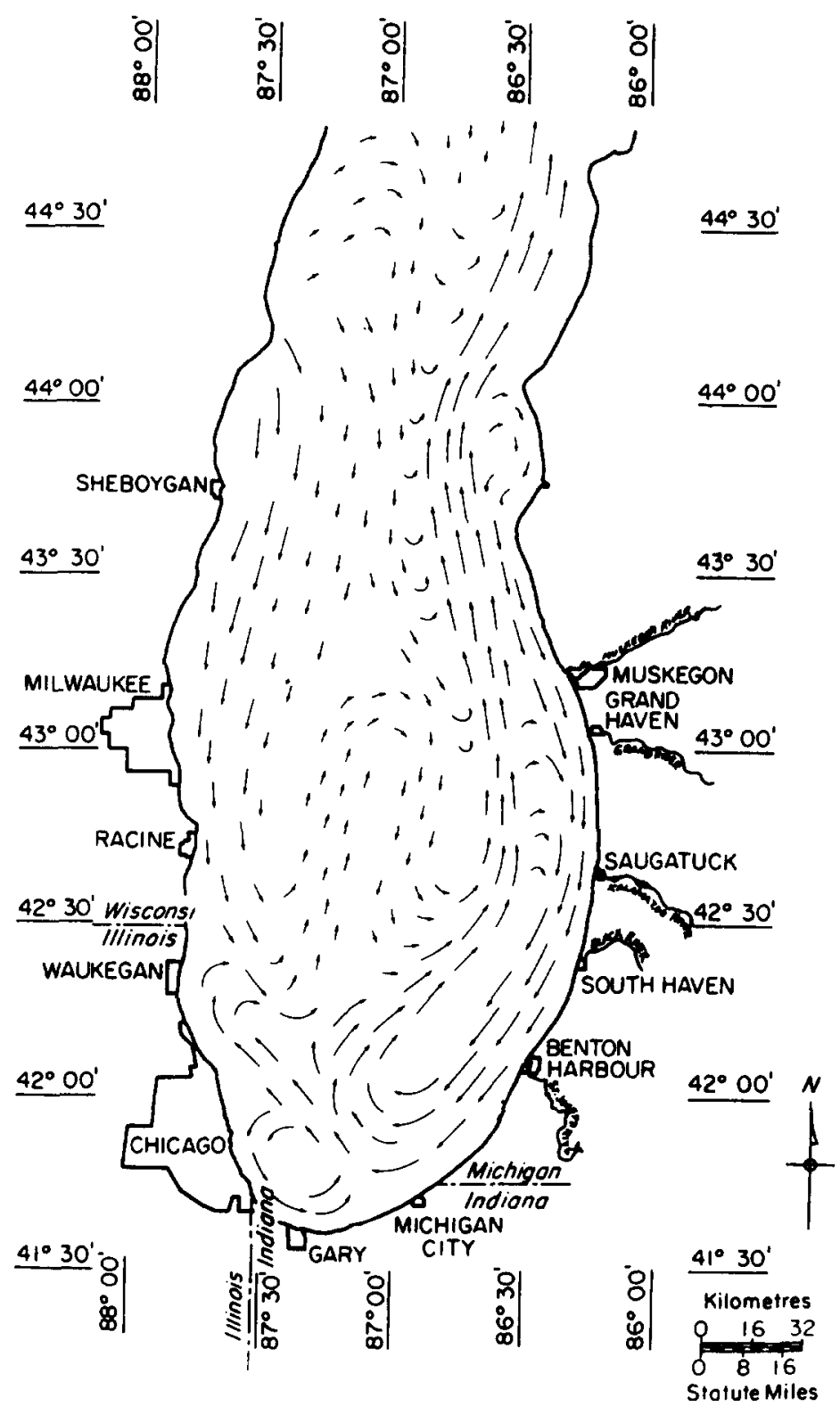

Fig. 4. Typical surface water current patterns for Lake Michigan (Ayers et al., 1958). 
sediment: sand, silty sand, layered, silt and hard. They found silt, the most recently deposited of the five types, in about the same area of sediment that we found to contain cesium-137 in concentrations greater than $1 \mathrm{pCi} / \mathrm{g}$, as shown in Fig. 2 . This relationship seems to support the idea of cesium-137 adsorbing onto suspended particles which eventually settle to the bottom to become what Powers \& Robertson classify as silt.

\section{CORRELATION OF CESIUM-137 WITH OTHER MATERIALS}

A variety of tracer materials has been used in environmental studies, including several radionuclides produced by atmospheric tests of nuclear weapons (Krishnaswami et al., 1973; Ritchie et al., 1973). Among the fallout radionuclides used, cesium-137 is an attractive tracer for sedimentation studies in the environment, for several reasons:

(1) It is produced in large amounts and distributed worldwide by detonations of nuclear weapons in the atmosphere.

(2) Its half-life $(30 y)$ is long compared with that required for environmental transport.

(3) No cesium-137 existed in the environment prior to 1945.

(4) It emits a gamma ray of sufficiently high energy $(0.66 \mathrm{MeV})$ to permit the quantitative analysis of an environmental sample without extracting the cesium-137 from the sample.

(5) The element, cesium, including the isotope, cesium-137, has a strong absorption affinity for the clay fraction of soil and sediment particles.

Twenty-five of the 530 sediment sampling stations shown in Fig. 1 were selected to determine if cesium-137 can be used as an environmental tracer to predict the areal distributions of other man-made materials in the sediments of a large lake. The results of the 1970 study (Plato, 1972) of Lake Michigan showed an average cesium-137 concentration of $1.43 \mathrm{pCi} / \mathrm{g}$ among the sediment samples collected uniformly throughout the lake. Only $8 \%$ of the samples had a cesium- 137 concentration greater than $4.00 \mathrm{pCi} / \mathrm{g}$. Therefore, the area of sediment near the mouth of the St Joseph River, shown in Fig. 2, containing more than $4.00 \mathrm{pCi} / \mathrm{g}$ is considered to be a high concentration area of cesium-137. Ten of the 25 samples analysed for other man-made materials were selected from within this high concentration area. The remaining 15 samples were selected from the sediment samples collected near the mouth of the St Joseph River but which contained less than $4.00 \mathrm{pCi} / \mathrm{g}$ of cesium-137.

Figure 5 shows the relative locations and station numbers of the 25 sediment sampling stations used to compare cesium-137 with other man-made materials. Two nuclear power plants are also shown in Fig. 5. At the time of this study, the Cook Plant was under construction and the Palisades Plant was undergoing low- 


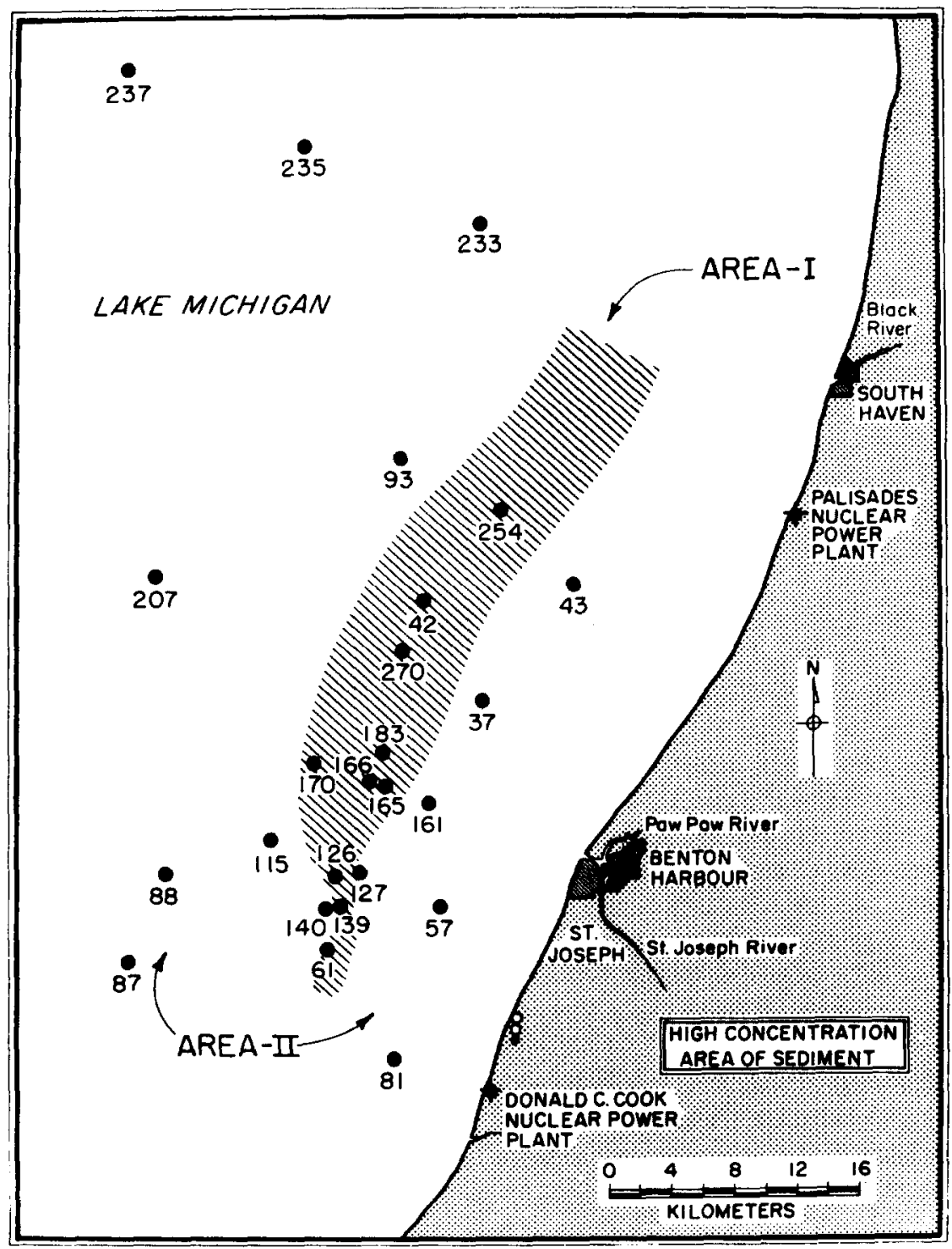

Fig. 5. The area of sediment (AREA-I) near the mouth of the St Joseph River was found to contain higher concentrations of cesium-137 than the background area (AREA-II). The relative locations and station numbers of the 25 sediment samples analysed for other man-made materials are also shown. 
TABLE 2

MATERIALS DISCHARGED BY MICHIGAN INDUSTRIES INTO THE ST JOSEPH RIVER AND AVERAGE CONCENTRATIONS IN THE RIVER

\begin{tabular}{lccc}
\hline Material & $\begin{array}{c}\text { Discharged } \\
\text { by Michigan } \\
\text { industries } \\
(\text { kg/y) }\end{array}$ & $\begin{array}{c}\text { Average } \\
\text { concentration } \\
\text { in river }\end{array}$ & $\begin{array}{c}\text { Total amount } \\
\text { discharged to } \\
\text { Lake Michigan } \\
(\text { kg/y) }\end{array}$ \\
\hline Metals & & & \\
Zinc & 7000 & $6 \cdot 9 \times 10^{-3} \mathrm{ppm}$ & 30000 \\
Nickel & 2500 & $17 \cdot 5 \times 10^{-3} \mathrm{ppm}$ & 75000 \\
Chromium & 650 & $2 \cdot 1 \times 10^{-3} \mathrm{ppm}$ & 9000 \\
Copper & 260 & $4 \cdot 2 \times 10^{-3} \mathrm{ppm}$ & 18000 \\
Lead & 190 & $4 \cdot 0 \times 10^{-3} \mathrm{ppm}$ & 17000 \\
Organic compounds & no data & $1 \cdot 0 \times 10^{-6} \mathrm{ppm}$ & 4 \\
Dieldrin & no data & $4 \cdot 2 \times 10^{-6} \mathrm{ppm}$ & 18 \\
DDT & no data & $13 \times 10^{-6} \mathrm{ppm}$ & 56 \\
PCB $^{\mathrm{e}}$ & & &
\end{tabular}

${ }^{a}$ Data obtained from Mr C. M. Fetterolf, Bureau of Water Management, Michigan Department of Natural Resources, Lansing.

b Concentrations of metals from (Robbins et al., 1972). Concentrations of organic compounds from Mr C. M. Fetterolf, Footnote a above.

c Assumes average river flow rate of 136000 litres/sec from Table 1.

d Dichlorodiphenyltrichloroethane.

e Polychlorinated biphenyls.

power testing. The 10 stations with cesium-137 concentrations greater than 4.00 $\mathrm{pCi} / \mathrm{g}$ are used to define the high concentration area of sediment, labelled AREA-I. The low concentration area is labelled AREA-II.

Aliquots from the 25 sediment samples selected near the mouth of the St Joseph River were analysed by the Bureau of Water Management, Michigan Department of Natural Resources, Lansing, Michigan, for five trace metals (zinc, copper, chromium, nickel and lead), two pesticides (dieldrin and DDT) and total PCB. These materials were chosen because data were available on amounts discharged into the St Joseph River by industries in Michigan and average concentrations in the river. These data are shown in Table 2. Additional aliquots from the 25 stations were analysed by the US Atomic Energy Commission's laboratory at Idaho Falls, Idaho, for the fallout radionuclides strontium-90, plutonium-238 and plutonium239.

As an initial step in analysing the data, regression analysis was used to obtain a correlation coefficient $(r)$ for cesium-137 compared with each of the other man-made materials for the 25 sediment samples selected. A correlation coefficient of 1.00 indicates a direct linear relationship between the two variables being tested, while a correlation coefficient of 0.00 indicates no relationship between the two variables. A correlation coefficient of -1.00 indicates an inverse relationship.

Table 3 shows correlation coefficients obtained using both the field and laboratory measurements for cesium-137. The results show good correlations $(r \geq 0 \cdot 50)$ between cesium-137 and plutonium-238, plutonium-239, zinc, copper, chromium 
TABLE 3

CORRELATION COEFFICIENTS ( $r$ ) OBTAINED BY REGRESSION ANALYSIS COMPARING FIELD AND LABORATORY MEASUREMENTS FOR CESIUM-137 WITH MEASUREMENTS FOR 11 OTHER MATERIALS MADE ON 25 SEDIMENT SAMPLES

\begin{tabular}{ccc}
\hline & \multicolumn{1}{c}{ Correlation coefficients for cesium-137 } \\
\cline { 2 - 3 } & Field $(\mathrm{cpm})$ & Lab $(\mathrm{pCi} / \mathrm{g})$ \\
\hline Radionuclides & & \\
Cesium-137 & & \\
Field (cpm) & 1.00 & 0.95 \\
Lab (pCi/g) & 0.95 & 1.00 \\
Strontium-90 (pCi/g) & 0.18 & 0.18 \\
Plutonium-238 (pCi/g) & 0.67 & 0.72 \\
Plutonium-239 (pCi/g) & 0.96 & 0.98 \\
Trace metals & & \\
Zinc (ppm) & 0.69 & 0.69 \\
Copper (ppm) & 0.52 & 0.66 \\
Chromium (ppm) & 0.87 & 0.88 \\
Nickel (ppm) & -0.46 & 0.22 \\
Lead (ppm) & 0.64 & 0.70 \\
Organic materials & & 0.32 \\
Dieldrin (10-3 ppm) & 0.34 & 0.26 \\
DDT (10-3 ppm) & 0.25 & 0.30 \\
PCB (10-3 ppm) & 0.31 & \\
\hline
\end{tabular}

TABLE 4

SUMMARY OF MEASUREMENTS MADE ON SEDIMENT SAMPLES FROM AREA-I AND AREA-II SHOWN IN FIG. 5

\begin{tabular}{|c|c|c|c|c|}
\hline Material & $\begin{array}{c}\text { Average of } \\
10 \text { Samples } \\
\text { from AREA-I }\end{array}$ & $\begin{array}{c}\text { Average of } \\
15 \text { Samples } \\
\text { from } A R E A-I I\end{array}$ & $\frac{A R E A-I}{A R E A-I I}$ & $\begin{array}{l}\text { AREA-I> } \\
\text { AREA-II at } \\
\text { following } \\
\text { conf. level } \\
(\%)\end{array}$ \\
\hline \multicolumn{5}{|l|}{$\begin{array}{r}\text { Radionuclides } \\
\text { Cesium-137 }\end{array}$} \\
\hline $\begin{array}{l}\text { Field (cpm) } \\
\text { Lab (pCi/g) }\end{array}$ & $\begin{array}{l}390 \pm 29^{a} \\
8.54 \pm 0.55\end{array}$ & $142 \pm 33^{a}$ & $2.75 \pm 0.67^{\mathrm{b}}$ & 99 \\
\hline$\underset{\text { Strontium-90 }}{\text { Lad }(\mathrm{pCi} / \mathrm{g})}$ & $0.235 \pm 0.045$ & $\begin{array}{l}3.19 \pm 0.68 \\
0.214 \pm 0.046\end{array}$ & $\begin{array}{l}2 \cdot 68 \pm 0.60 \\
1 \cdot 10 \pm 0.32\end{array}$ & 99 \\
\hline $\begin{array}{l}\text { Plutonium-238 } \\
(\mathrm{pCi} / \mathrm{g})\end{array}$ & $0.00601 \pm 0.00083$ & $0.00254 \pm 0.00079$ & $2.37 \pm 0.08$ & 99 \\
\hline \multicolumn{2}{|c|}{$\underset{\text { Trace metals }}{\text { Plutonium-239 }(\mathrm{pCi} / \mathrm{g}) 0 \cdot 130 \pm 0.009}$} & $0.051 \pm 0.011$ & $2.55 \pm 0.59$ & 99 \\
\hline Zinc (ppm) & $261 \pm 54$ & $149 \pm 19$ & $1.75 \pm 0.43$ & 95 \\
\hline Copper (ppm) & $32 \cdot 7 \pm 1 \cdot 3$ & $25 \cdot 2 \pm 3 \cdot 1$ & $1 \cdot 30 \pm 0.17$ & 90 \\
\hline Chromium (ppm) & $43 \cdot 2 \pm 1 \cdot 5$ & $21 \cdot 5 \pm 1 \cdot 8$ & $2.01 \pm 0.18$ & 99 \\
\hline Nickel (ppm) & $12 \cdot 0 \pm 1 \cdot 3$ & $15 \cdot 3 \pm 1 \cdot 3$ & $0.78 \pm 0.11$ & - \\
\hline $\begin{array}{l}\text { Lead (ppm) } \\
\text { Organic materials }\end{array}$ & $98 \cdot 0 \pm 2 \cdot 0$ & $64 \cdot 3 \pm 4 \cdot 9$ & $1.52 \pm 0.12$ & 99 \\
\hline \multirow{3}{*}{$\begin{array}{l}\text { Organic materials } \\
\text { Dieldrin }\left(10^{-3} \mathrm{ppm}\right) \\
\text { DDT }\left(10^{-3} \mathrm{ppm}\right) \\
\text { PCB }\left(10^{-3} \mathrm{ppm}\right)\end{array}$} & & +0.05 & 1.3 & 95 \\
\hline & $19.1 \pm 4.5$ & $9.8 \pm 2.1$ & $1.95+0.62$ & 95 \\
\hline & $48.5 \pm 8.4$ & $29 \cdot 7 \pm 3 \cdot 3$ & $1.63 \pm 0.34$ & 95 \\
\hline
\end{tabular}

" Error values represent sample standard deviations.

- Propagated standard deviations. 
and lead. Poor correlations $(r<0.50)$ are found between cesium-137 and strontium-90, nickel, dieldrin, DDT and PCB.

The analysis of variance test was used to determine if any of the materials, in addition to cesium-137, had significantly higher concentrations in the sediments of AREA-I than in the sediments of AREA-II shown in Fig. 5. Table 4 contains a summary of the 13 measurements (including field and laboratory measurements for cesium-137) made on the 10 sediment samples from AREA-I and the 15 sediment samples from AREA-II. Nine of the 11 materials examined in addition to cesium137 have higher concentrations in the sediment samples from AREA-I than from AREA-II. Chromium, lead, plutonium-238 and plutonium-239 are higher in AREA-I than in AREA-II at the $99 \%$ confidence level. Zinc, dieldrin, DDT and PCB are higher at the $95 \%$ confidence level, and copper is higher at the $90 \%$ confidence level.

\section{DISCUSSION}

The results shown in Figs. 2, 3 and 4 and in Table 1 suggest that four primary mechanisms are probably responsible for the areal distribution of cesium-137 in the sediments of Lake Michigan. These are: (1) adsorption of cesium-137 onto suspended solids; (2) discharge rates of suspended solids by surrounding river: (3) water current patterns in the lake; and (4) the effects of storms in the shallow waters around the periphery of the lake. The interactions of these mechanisms are not understood well enough to explain completely the cesium-137 distributions shown in Fig. 2.

The same mechanisms responsible for the areal distribution of cesium-137 are probably responsible for the areal distributions of other man-made materials in bottom sediments. However, natural concentrations of some metals may occur in certain areas of sediment due to geochemical factors independent of the activities of man.

In an attempt to determine if cesium-137 can be used as an environmental tracer to predict the areal distributions of other man-made materials, 25 of the 530 sediment samples collected were analysed for a total of 12 radionuclides, metals and organic compounds. Two methods were used to interpret the results. Correlation coefficients were calculated between cesium-137 and the other materials measured, and the analysis of variance test was used to determine which of the other materials have significantly higher concentrations in the sediments of AREA-I (Fig. 5) than in surrounding sediments.

Fallout cesium-137 appears to be a good tracer to locate areas of accumulation of plutonium-238, plutonium-239, zinc, copper, chromium and lead in sediment. These six materials have correlation coefficients with cesium-137 greater than 0.50 , 
and are found in high concentrations in the sediments near the mouth of the St Joseph River that contain high concentrations of cesium-137, as shown in Table 4.

Fallout cesium-137 appears to be a moderate tracer to locate areas of accumulation of dieldrin, DDT and PCB in sediment. The correlation coefficients between these materials and cesium- 137 are less than 0.50 , but the materials are found in high concentrations in the sediments near the mouth of the St Joseph River that contain high concentrations of cesium-137.

Fallout cesium-137 appears to be a poor tracer to locate areas of accumulation of strontium-90 and nickel in sediment. The correlation coefficients between these materials and cesium- 137 are less than $0 \cdot 50$, and no area of sediment near the mouth of the St Joseph River contains higher concentrations of these materials than surrounding areas. Table 2 shows that large amounts of nickel are discharged into the river by industry, and nickel is found in the river water in relatively high concentrations. Nickel apparently remains dissolved in the river and lake waters to a much greater extent than does cesium-137. Studies described by Straub (1964) show that cesium-137 has a higher adsorption affinity for suspended soil particles than does strontium- 90 since atoms of cesium become incorporated in the crystal lattice structure of clay minerals. Therefore, it is not unreasonable to observe a lack of correlation between cesium-137 and strontium-90 in the sediment samples studied.

Shimp et al. (1971) collected 43 grab and core samples of sediment from southern Lake Michigan. The core samples were separated into $3 \mathrm{~cm}$ sections to a depth of $18 \mathrm{~cm}$. The core sections and grab samples were then analysed for 12 trace elements. Shimp et al. found the highest concentrations of lead, zinc, chromium and copper in the superficial sediments located approximately 8 to $20 \mathrm{~km}$ offshore from the mouth of the St Joseph River, about the same area shown in Fig. 2 to contain the highest concentrations of cesium-137. Nickel was not found in higher concentrations in the superficial sediments of this area than in other areas of Lake Michigan. Furthermore, Shimp et al. found substantially higher concentrations of lead, zinc, chromium and copper in the superficial sediments than in the deeper core sections. They interpret the higher concentrations in the upper layers of sediment as an indication of man's activities. Nickel was found in about the same concentrations in all sections of a given sediment core, which implies that most of the nickel discharged by man into Lake Michigan remains dissolved in the waters of the lake.

\section{CONCLUSION}

The areal distribution of cesium-137 in the sediments of Lake Michigan, particularly in the southeastern quarter, is shown in Fig. 2 with greater detail than was previously possible when only 50 sampling stations were used to measure the sediments of the lake. Detailed mapping (Fig. 2) to show areas of sediment that contain high and 
low concentrations of cesium-137 is possible only when many samples are collected per unit area surveyed (Fig. 1).

The comparison of concentrations of cesium-137 to concentrations of other man-made materials in the 25 sediment samples selected near the mouth of the St Joseph River is not meant to represent a definitive examination of the usefulness of fallout cesium-137 as an environmental tracer for sedimentation studies. However, the results of this pilot study do show some promise for the use of cesium-137, which can be measured rapidly and inexpensively in the field. A study of the mechanisms that cause the accumulation of cesium-137 and other man-made materials in localised areas of sediment is required to determine for which materials and under what circumstances cesium-137 can be used as a tracer.

\section{ACKNOWLEDGEMENTS}

The authors express their gratitude to Mr Carlos M. Fetterolf and Mr John Hesse of the Bureau of Water Management, Michigan Department of Natural Resources, for their co-operation and to Bureau chemists, Dr James Bedford and M. T. K. Wu, for the trace metal and organic compound analyses they performed on aliquots of the sediment samples. Similar gratitude is extended to $\mathrm{Mr}$ Claude $\mathrm{W}$. Sill of the US Atomic Energy Commission's Idaho Operations Office for the analyses performed on aliquots of the same samples for strontium-90, plutonium-238 and plutonium-239.

\section{REFERENCES}

Ayers, J. C., Chandler, D. C., Lauff, G. H., Powers, C. F. \& Henson, E. B. (1958). Currents and water masses of Lake Michigan. Publs Univ. Mich., Ann Arbor, Great Lakes Res. Div., No. 3, 53 .

Chow, T. J., Bruland, K. W., Bertine, K., Soutar, A., Koide, M. \& Goldberg, E. D. (1973). Lead pollution: records in southern California coastal sediments. Science, N.Y., 181, 551-2.

Golden, J. C., Plato, P. A. \& Whipple, G. H. (1970). Lake Michigan Environmental Survey, Chapter A, Univ. Mich., Ann Arbor, Great Lakes Res. Div. Special Report, No. 49.

Krishnaswami, S., Lal, D., Amin, D. S. \& Soutar, A. (1973). Geochronological studies in Santa Barbara basin: Iron-55 as a unique tracer for particulate settling. Limnol. Oceanogr., $18,763-70$.

Plato, P. A. (1972). Distribution of cesium-137 and naturally occurring radionuclides in sediments of Lake Michigan. Radiation data and reports, 13, 181-7.

Plato, P. A. \& Goldman, G. C. (1972). Use of fallout cesium-137 as a tracer to define the recent deltaic facies of a river. Radiation data and reports, 13, 653-7.

Powers, C. F. \& Robertson, A. (1968). Subdivisions of the benthic environment of the upper Great Lakes, with emphasis on Lake Michigan. J. Fish. Res. Bd Can., 25, 1181-97.

Ritchie, J. C., MCHenry, J. R. \& Gill, A. C. (1973). Dating recent reservoir sediments. Limnol. Oceanogr., 18, $254-63$.

Robbins, J. A., Lanstrom, E. \& Wahlgren, M. (1972). Tributary inputs of soluble trace metals to Lake Michigan. Proc. Conf. Great Lakes Res., 15th, 270-90, University of Michigan, Ann Arbor, Great Lakes Research Division. 
Robins, J. A. \& Edgington, D. N. (1975). Determination of recent sedimentation in Lake Michigan using lead-210 and cesium-137. Geochim. cosmochim. Acta, 39, 285-304.

Shimp, N. F., Schleicher, J. A., Ruch, R. R., Heck, D. B. \& Leland, H. V. (1971). Trace element and organic carbon accumulation in the most recent sediments of southern Lake Michigan. Illinois State Geological Survey, Urbana, Environmental Geology Notes, No. 41.

State OF Michigan (1968). Water Quality Monitoring Program, Water Quality Records. Bureau of Water Management, Department of Natural Resources, Lansing.

StRAUB, C. P. (1964). Low-level radioactive wastes, p. 109. Washington, D.C., US Atomic Energy Commission, Division of Technical Information. 